\section{Isolation of Rhamnose Derivatives from Ulva lactuca}

WorkING on algæ other than the Chlorophyceæ, various investigators have established the existence of algal polysaccharides containing mannuronic, galactose or fucose residues, the two latter being in the form of sulphuric acid esters. An investigation of Ulva lactuca, a member of the Chlorophyceæ, undertaken with the hope of ultimate correlation with pigmentation, has unexpectedly revealed the presence of a rhamnose polysaccharide, hitherto unknown among algal products.

Without a complete purification of the weakly acidic, non-reducing Ulva carbohydrate, evidence was obtained for an acid sulphuric ester structure and the absence of uronic acid residues. By furfural estimation a methyl pentose content of approximately 25 per cent was established, and on hydrolysis by dilute acids, preferential fissure of the methyl pentose residues occurred to some extent.

Rhamnose was identified as a constituent of the hydrolysate, by a fractional distillation after methylation of the syrupy sugar mixture, and the subsequent isolation of crystalline $2: 3: 4$-tri-methyl rhamnose anilide and 2:3:4-tri-methyl rhamnose phenyl hydrazone.

Interruption of this work has prevented the complete identification of a very labile constituent of the hydrolysate. Investigation of the other hydrolysis products, together with an investigation of the methylated polysaccharide, will be undertaken as soon as the work can be resumed.

M. M. T. Plant.

E. D. Johnson.

\section{Royal Holloway College, Englefield Green, Surrey. March 3.}

\section{Tadpoles out of Season}

BY pituitary treatment of an appropriate species of Rana at the appropriate time of year it has been shown by Rugh ${ }^{1}$ in the United States that fertilized eggs and developing tadpoles can be obtained the whole year round. I have found that during the winter months (November-February) fertilized eggs and tadpoles of Rana temporaria can be readily obtained by the same methods, although the reaction of this species to pituitary treatment is somewhat different.

Briefly, Rugh's techniqueis to inject in saline the whole partes anteriores of pituitaries freshly excised from frogs of the same species, into the coelomic cavity of the adult frog by means of a large hypodermic needle. By controlling the dose and time of injection, amplexus in the male can be made to synchronize with ovulation in the female. In the frogs used by Rugh (Rana pipiens, $R$. clamitans, R. catesbeiana, R. sphenocephala, Acris gryllus) egglaying follows treatment within twenty-four hours at room temperature, although it may be delayed up to five days by smaller doses. In $R$. temporaria, however, a period of about twenty-one days elapses between injection and egg-laying in the female and about eighteen days between injection and amplexus in the male, so that fertilized eggs may be expected about the twenty-first day. Moreover, these times appear to be little affected by variations in dosage, so that control is simple. A single peritoneal injection of 0.25 c.c. of saline containing anything from three to six glands excised from adult females will produce ovulation or amplexus. Six glands excised from adult males will suffice instead. When the frogs bejin to copulate each pair should be placed in a separate vessel containing fresh pond water. After the spawn is shed and fertilized some three days later, the frogs should be removed. The tadpoles produced in this way appear to be in every respect normal.

Department of Biology,

H. Metten.

St. Bartholomew's Medical College, at

The Zoology Laboratiory, Cambridge. Feb. 28.

${ }^{1}$ Rugh, R., Science, 85, 588-589 (1937).

\section{Soil Protozoa in some Chinese Soils}

Forty soil samples collected around Kiating and its vicinity, Szechuen, have been studied. Fifty-seven species of Protozoa were recorded: 24 species flagellates, 10 species Sarcodina and 23 species ciliates. Among them, several species were found for the first time in soil. They are, among the flagellates, Cryptochrysis commutata, Peridinium sp.; among the Sarcodina, Amceba guttula, Amoeba striata; and among the ciliates, Frontonia sp., Chilodon capucinus, Chilodon fuviatilis, Vorticella chlorostigma, $V$ orticella nutans. The most common species found are Oikomonas termo, Monas vulgaris, Amoba limax, Hartmanella hyalina, Cercomonas longicauda, Noegleria gruberi and Colpoda cucullus. They are present in 70-100 per cent of the samples examined. Casual observations indicate that the greatest number of species found in one single sample is around seventeen, and the least one or two.

The numbers of Protozoa per gram of soil were determined by the dilution method for twenty soil samples. The highest number found was 112,500 (rice field, clay) and the smallest number 65 (barren sand, loamy sand). Flagellates are present in far greater numbers than the Sarcodina and ciliates.

\section{H. ZANYIN GaW.}

Physiological Laboratory,

National Wuhan University, Kiating, Szechuen. Oct. 1 .

\section{Discreteness of Sensations}

In 1938 I observed the fluctuation of the threshold of hearing ${ }^{1}$. As proved by recent experiments, this phenomenon is also applicable in the field of vision and touch, and is characterized by the discreteness of sensations.

The phenomenon has been investigated in the following way. The observer receives auditory, visual or tactual impulses of equal duration $(0.3 \mathrm{sec}$.) at equal intervals $(0.45 \mathrm{sec}$.$) . As the force of the im-$ pulse decreases, the impulses become less clear or loud, and they seem to be of lesser duration, according to the integral law of apparent duration ${ }^{2}$, but all 